\title{
Side Chain vs. Main Chain. Who Dominates? A Polyester-Grafted Poly(paraphenyleneethynylene) With Two Different Morphologies
}

Yunfei Jiang, Dvora Perahia*

Department of Chemistry, Clemson University, Clemson SC 29634, USA

Yiqing Wang, Uwe H. F. Bunz*

School of Chemistry and Biochemistry, Georgia Institute of Technology, 770 State Street, Atlanta GA 30313, USA

*e-mail: uwe.bunz@chemistry.gatech.edu,dperahi@chemistry.clemson.edu

\section{SUPPORTING INFORMATION}

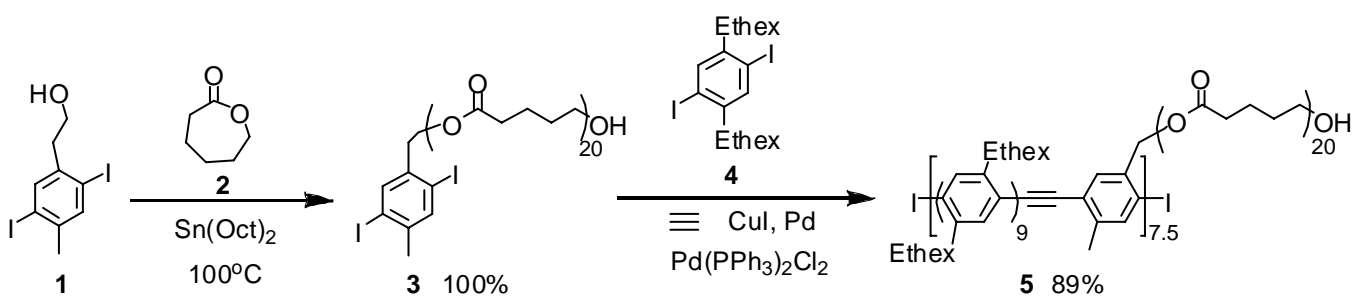

Macromonomer 3: An oven-dried Schlenk flask cooled under nitrogen was charged with 1 (54 $\mathrm{mg}, 0.14 \mathrm{mmol})$, $\varepsilon$-caprolactone $2(319 \mathrm{mg}, 2.80 \mathrm{mmol})$, and tin(II)-2-ethylhexanoate (1 mg, 2 $\mu \mathrm{mol})$. The flask was heated while stirring to $100^{\circ} \mathrm{C}$. The reaction was stopped after $12 \mathrm{~h}$. The reaction mixture was dried under vacuum at $60^{\circ} \mathrm{C}$ overnight. The macromononer 3 was obtained as a colorless solid (373 mg, 100\%). GPC (vs. polystyrene standards in chloroform): $M_{n}=2400$, $\mathrm{M}_{\mathrm{w}} / \mathrm{M}_{\mathrm{n}}=1.1 . \mathrm{IR}\left(\mathrm{KBr}, \mathrm{cm}^{-1}\right): v 2941,2893,2866,1722,1683,1652,1506,1471,1456,1394$, 1294, 1244, 1190, 1107, 1045, 962, 933, 877, 840, 731, 709. ${ }^{1} \mathrm{H} \mathrm{NMR}\left(\mathrm{CDCl}_{3}, 400 \mathrm{MHz}\right): \delta=$ $7.67(\mathrm{~s}, 1 \mathrm{H}), 7.63(\mathrm{~s}, 1 \mathrm{H}), 4.24(\mathrm{t}, 2 \mathrm{H}), 4.05(\mathrm{t}, 38 \mathrm{H}), 3.64(\mathrm{t}, 2 \mathrm{H}), 2.98(\mathrm{t}, 2 \mathrm{H}), 2.30(\mathrm{t}, 40 \mathrm{H})$, $1.68-1.60(\mathrm{~m}, 80 \mathrm{H}), 1.41-1.33(\mathrm{~m}, 40 \mathrm{H}) .{ }^{13} \mathrm{C} \mathrm{NMR}\left(\mathrm{CDCl}_{3}, 400 \mathrm{MHz}\right): \delta=173.73,173.54$, 173.29, 141.91, 139.91, 139.87, 139.82, 100.76, 100.03, 64.54, 64.14, 63.95, 63.10, 62.62, 38.64, $34.23,34.12,33.95,33.82,33.34,28.53,28.35,28.18,26.96,25.93,25.53,25.31,24.98,34.69$, 24.58, 24.39. Calcd. C 58.01, H 7.92. Found. C 57.95, H 7.83.

Polymer 5: 3 (373 mg, $0.155 \mathrm{mmol}$, counted by monomer 1) was combined with 4 (698 $\mathrm{mg}$, $1.26 \mathrm{mmol})$, piperidine $(1.5 \mathrm{~mL})$, THF $(1.5 \mathrm{~mL}),\left(\mathrm{PPh}_{3}\right)_{2} \mathrm{PdCl}_{2}(2 \mathrm{mg}, 3 \mu \mathrm{mol}, 0.2 \mathrm{~mol} \%)$ and $\mathrm{CuI}(1 \mathrm{mg}, 5 \mu \mathrm{mol}, 0.4 \mathrm{~mol} \%)$ in a Schlenk flask $(37 \mathrm{~mL})$. Acetylene gas $(34 \mathrm{~mL}, 1.40 \mathrm{mmol})$ was added through the purged side arm with a balloon. The reaction was allowed to stir at room temperature for $24 \mathrm{~h}$. The reaction mixture was extracted with dichloromethane $(50 \mathrm{~mL})$ and washed with ammonium hydroxide $(10 \%, 2 \times 50 \mathrm{~mL})$, and $\mathrm{HCl}(10 \%, 50 \mathrm{~mL})$. The organic layer was dried over $\mathrm{MgSO}_{4}$ and concentrated under reduced pressure. The remaining mixture $(10 \mathrm{~mL})$ was precipitated from acidified methanol. The polymer was collected over a fritted funnel, re-dissolved in dichloromethane and re-precipitated from acidified methanol. A flaky yellow polymer, 5, was obtained $(0.591 \mathrm{~g}, 79 \%$ yield). GPC (vs. polystyrene standard in chloroform): $\mathrm{M}_{\mathrm{n}}=4.6 \times 10^{4}, \mathrm{P}_{\mathrm{n}}=86, \mathrm{M}_{\mathrm{w}} / \mathrm{M}_{\mathrm{n}}=5.6 .{ }^{1} \mathrm{H}$ NMR $\left(400 \mathrm{MHz}, \mathrm{CDCl}_{3}\right): \delta=7.41$ (bs), 4.04 (bt), 3.62 (bt), 3.49 (s), 2.76 (bs), 2.32-2.28 (bt), 1.62-1.40 (bm), 1.36-0.90 (bm). ${ }^{13} \mathrm{C} \mathrm{NMR}$ $\left(400 \mathrm{M} \mathrm{Hz}, \mathrm{CDCl}_{3}\right): \delta=173.69,141.01,133.35,123.85,123.18,93.46,92.54,65.15,64.09$, 63.05, 62.55, 40.28, 38.56, 34.06, 32.27, 28.804, 28.29, 25.47, 23.10, 25.25, 24.52, 20.29, 14.10, 10.83. Calcd. C 77.73, H: 10.04. Found C 78.94, H: 10.98. 


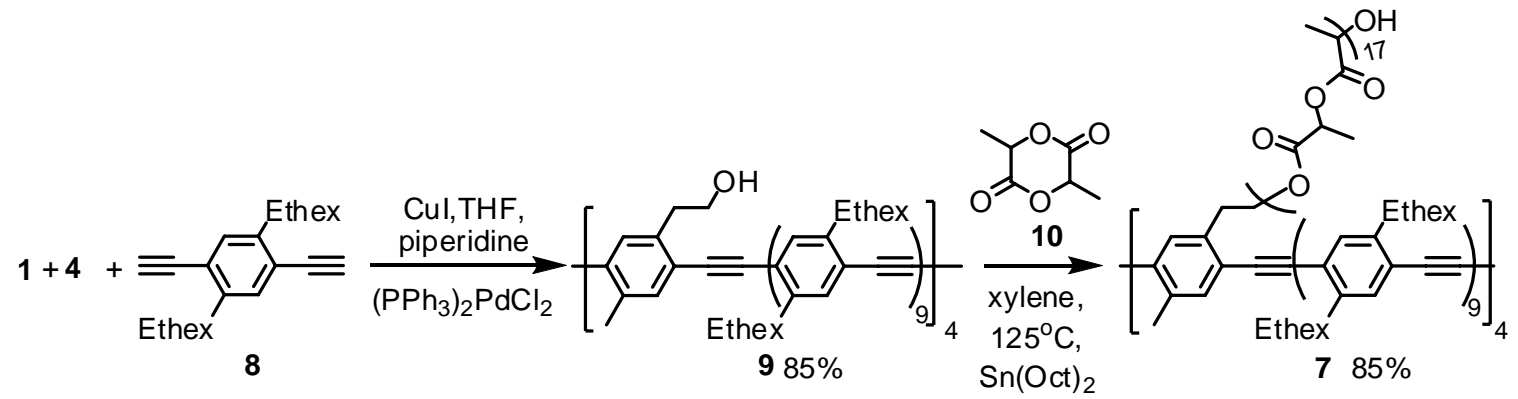

Polymer 9: An oven-dried Schlenk flask cooled under nitrogen was charged with 1 (194 mg, $0.50 \mathrm{mmol}), 4(1.109 \mathrm{~g}, 2.00 \mathrm{mmol}), 8(0.876 \mathrm{~g}, 2.50 \mathrm{mmol})$, THF $(5 \mathrm{~mL})$, piperidine $(1.50 \mathrm{~mL})$, $\left(\mathrm{PPh}_{3}\right)_{2} \mathrm{PdCl}_{2}(2 \mathrm{mg}, 3 \mu \mathrm{mol})$ and $\mathrm{CuI}(1 \mathrm{mg}, 5 \mu \mathrm{mol})$. The flask was degassed and filled with nitrogen. The reaction was allowed to stir at room temperature for $24 \mathrm{~h}$. The reaction mixture was filtered over a $1 \mathrm{~cm}$ thick plug of silica on a fritted funnel and washed thoroughly with hexane. After hexane evaporated, the crude product was dissolved in chloroform $(10 \mathrm{~mL})$, and added drop-wise into methanol $(300 \mathrm{~mL})$. A bright yellow solid, 9, (1.34 g, 87\%) was obtained. GPC (vs. polystyrene standards in chloroform): $\mathrm{M}_{\mathrm{n}}=1.3 \times 10^{4}, \mathrm{M}_{\mathrm{w}} / \mathrm{M}_{\mathrm{n}}=3.1 .{ }^{1} \mathrm{H} \mathrm{NMR}\left(\mathrm{CDCl}_{3}\right)$ : $\delta=7.46$ (bs), 7.42-7.20 (bm), 4.00 (bt), 2.93-2.61 (bm), 2.53 (bs), 1.90-1.05 (m), 1.40-0.90 (bm), 0.85-0.75 (bd). ${ }^{13} \mathrm{C}-\mathrm{NMR}\left(\mathrm{CDCl}_{3}\right): \delta=141.29,133.25,123.07,93.38,62.83,40.28,38.58$, $32.48,28.80,25.60,23.10,14.10,10.83$. Anal. Calcd. C 88.55, H 10.93. Found C 87.52, H: 11.03

Polymer 7: 9 (0.500 g, $0.16 \mathrm{mmol}$, counted by monomer 1) was added to xylene (5 $\mathrm{mL})$ in a pressure tube at $125^{\circ} \mathrm{C}$ under nitrogen flow. After $30 \mathrm{~min}$, lactide 10 (0.500 g, $\left.3.47 \mathrm{mmol}\right)$, tin(II)-2-ethylhexanoate $(13 \mathrm{mg}, 31 \mu \mathrm{mol})$ was added, and the pressure tube was sealed. The reaction was heated under stirring to $125^{\circ} \mathrm{C}$ for $24 \mathrm{~h}$. The reaction mixture was precipitated from acidified methanol $(100 \mathrm{~mL})$. Polymer 7 was obtained as a green-yellow fluorescent solid (0.853 g, 85\%). GPC (vs. polystyrene standards in chloroform): $M_{n}=2.6 \times 10^{4}, M_{w} / M_{n}=2.9 . P_{n}=21$ ${ }^{1} \mathrm{H}$ NMR $\left(\mathrm{CDCl}_{3}, 400 \mathrm{MHz}\right): \delta=7.42-7.20(\mathrm{bm}), 5.35-4.90(\mathrm{bm}), 2.93-2.61(\mathrm{bm}), 1.90-1.05(\mathrm{~m})$, 1.60-1.40 (bm), 1.40-0.90 (bm), 0.85-0.75 (bd). ${ }^{13} \mathrm{C} \mathrm{NMR}\left(\mathrm{CDCl}_{3}, 400 \mathrm{MHz}\right): \delta=169.48$, $141.01,133.82$, 124.05, 93.40, 69.05, 40.28, 38.56, 32, 47, 28.80, 25, 60, 23.10, 20.47, 16.61, $14.10,10.90$.

\section{Preparation of films}

The samples for AFM were obtained by dip-coating films onto oxidized single crystal silicon wafer substrates from solutions of polymer 5-7 in chloroform $(0.1 \mathrm{wt} \%)$. The sample films were then dried at ambient condition and pumped down in vacuum to remove residual solvent. The annealing process was carried out in a vacuum oven under $\mathrm{N}_{2}$ atmosphere for $2 \mathrm{~min}, 5 \mathrm{~min}$ and $15 \mathrm{~min}$. after which the films were cooled to room temperature.

\section{Characterization}

The ${ }^{1} \mathrm{H}$ and ${ }^{13} \mathrm{C}$ NMR were taken on a Varian $300 \mathrm{MHz}$ spectrometer using a broadband probe. IR data were collected by a FTIR-8400S infrared spectrophotometer (Shimadzu). The emission spectra were taken by RF-5301 PC Spectrofluorophotometer (Shimadzu). GPC measurements were conducted in chloroform $\left(25^{\circ} \mathrm{C}\right)$ with a SCL-10A VP UV-VIS detector (Shimadzu). The molecular weights were determined versus polystyrene standards. AFM measurements were carried out on a digital multi-mode AFM in the tapping mode at room temperature. Olympus cantilevers, OMCL-AC160TS, with a spring constant of $42 \mathrm{~N} / \mathrm{m}$, resonating at around $300 \mathrm{kHz}$, have been used for all measurements. The strength of the tapping was varied to meet the needs of the specific samples. 
Table 1: Raw data of the DSC of 5

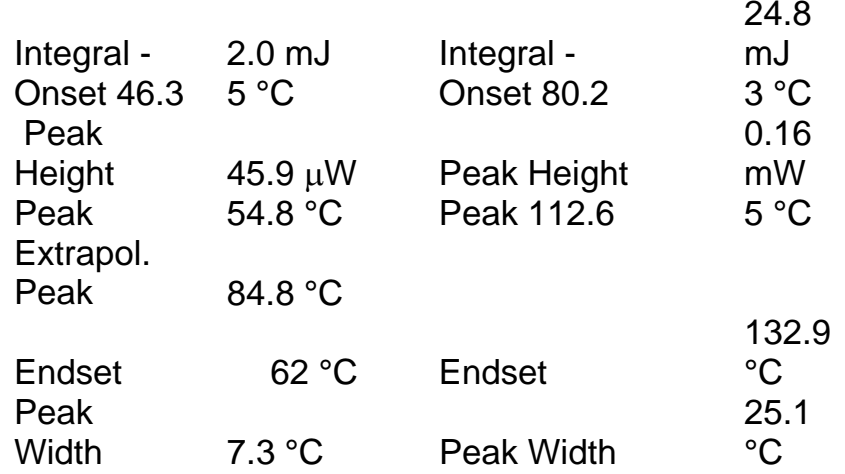

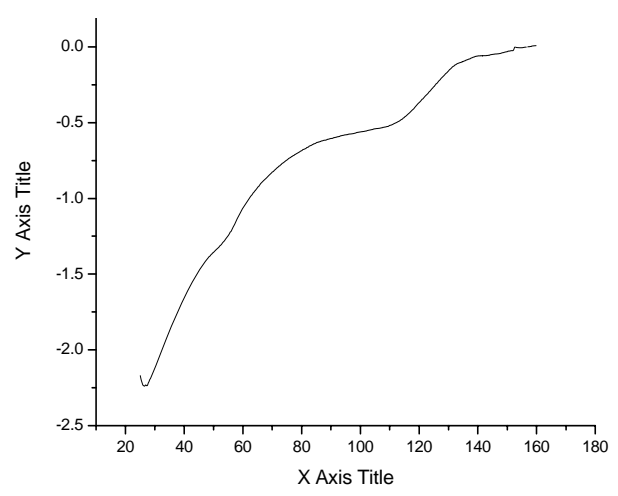

Figure 1. DSC data of 5. Two peaks observed: $85^{\circ} \mathrm{C}\left(\mathrm{Tg}\right.$ of polycaprolactone) and $130^{\circ} \mathrm{C}(\mathrm{Tg}$ of PPE main chains).

Table 2. Raw data of the DSC of 9

$\begin{array}{llll}\text { Integral } & -2.55 \mathrm{~mJ} & \text { Integral } & -66.9 \mathrm{~mJ} \\ \text { Onset } & 43.9^{\circ} \mathrm{C} & \text { Onset } & 109.4^{\circ} \mathrm{C} \\ \text { Peak Height } & \mathrm{t} 46.89 \mu \mathrm{W} & \text { Peak Height } & 0.5 \mathrm{~mW} \\ \text { Peak } & 54.8^{\circ} \mathrm{C} & \text { Peak } & 129.4^{\circ} \mathrm{C} \\ \text { Extrapol. Peak } & 68.7^{\circ} \mathrm{C} & \text { Extrapol. Peak } & 132.0^{\circ} \mathrm{C} \\ \text { Endset } & 64.66^{\circ} \mathrm{C} & \text { Endset } & 136.2^{\circ} \mathrm{C} \\ \text { Peak Width } & 8.8^{\circ} \mathrm{C} & \text { Peak Width } & 21.7^{\circ} \mathrm{C}\end{array}$

Figure 2. DSC data of 9 . Two peaks are observed: $68^{\circ} \mathrm{C}$

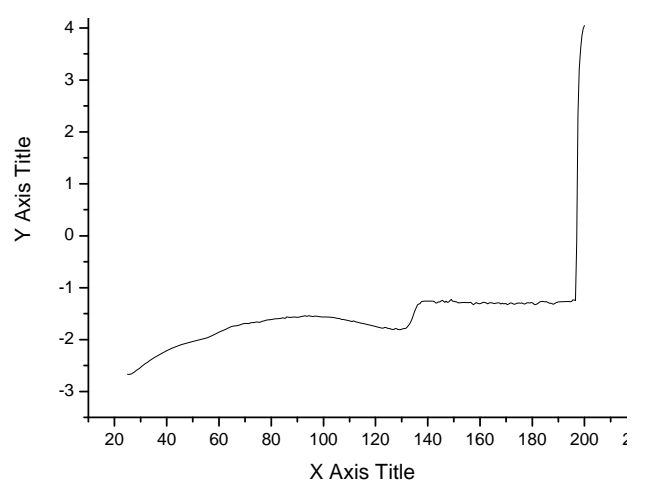
(Tg of polylactide); $132^{\circ} \mathrm{C}$ ( $\mathrm{Tg}$ of PPE main chains)

To exclude that the ring-structures were artifacts of the AFM work, height profiles of several samples of the annealed and the pristine films at varying tapping strengths were taken. Figure 3 shows a representative example:
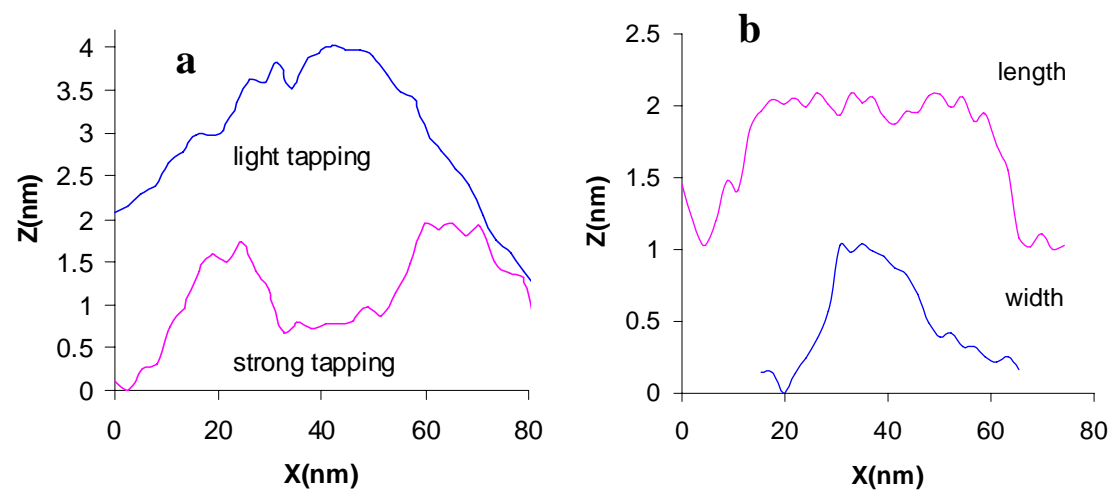

Figure 3. Representative AAFM-traces of the features observed in Figure $1 \mathrm{a}$-c for the polymer 4. a) The light tapping (blue) corresponds to Figure 1a and shows that spherical species protrude the surface of the film, the strong tapping (purple) corresponds to Figure $1 \mathrm{~b}$ and shows that under strong tapping the spheres are crushed and visible as rings. b) Geometric dimensions of the extended morphology of $\mathbf{4}$ after annealing to show the length (purple) and the width (blue) of the produced needle-like species. 